\title{
A PRESCRIÇÃO DE MEDICAMENTOS PELOS ENFERMEIROS NA ESTRATÉGIA SAÚDE DA FAMÍLIA*
}

\author{
Renata Borges de Vasconcelos ${ }^{1}$ Janieiry Lima de Araújo²
}

\begin{abstract}
RESUMO: Estudo qualitativo que objetivou discutir os limites e possibilidades da prescrição de medicamentos por enfermeiros na Estratégia Saúde da Família. Foram entrevistados 11 enfermeiros e a interpretação das informações por meio da Análise Temática resultou em cinco categorias empíricas. Os enfermeiros se sentem capacitados para prescrever medicamentos na consulta de enfermagem; para eles a prescrição traz autonomia e valorização profissional e necessita de cautela quando executada, para não trazer riscos à saúde dos usuários. Tal prática ocorre nos programas de saúde pública, porém falta apoio legal da gestão de saúde sobre o tema. Faz-se necessário o diálogo entre a gestão, os enfermeiros e os órgãos representativos da categoria para que a prescrição de medicamentos seja realizada com ética e responsabilidade com vistas ao cuidado coletivo de saúde. DESCRITORES: Enfermagem; Cuidados de enfermagem; Prescrição de medicamentos; Saúde da família; Ética em enfermagem.
\end{abstract}

\section{THE PRESCRIPTION OF MEDICINES BY THE NURSES IN THE FAMILY HEALTH STRATEGY}

ABSTRACT: This qualitative study aimed to discuss the limits and possibilities of the prescription of drugs by nurses in the Family Health Strategy. 11 nurses were interviewed, and the interpretation of the information using Thematic Analysis resulted in five empirical categories. The nurses feel able to prescribe drugs in the nursing consultation; for them, the prescribing brings autonomy and professional valorization and needs caution when undertaken so as not to entail risks to the health of the service users. This practice occurs in the public health programs, but legal support from the health managers on the issue is lacking. Dialog is needed between management, the nurses, and the representative bodies of that category so that the prescription of drugs may be undertaken ethically and responsibly, with a view to public health care.

DESCRIPTORS: Nursing; Nursing care; Prescription of drugs; Family health; Ethics in Nursing.

\section{PRESCRIPCIÓN DE MEDICINAS POR LOS ENFERMEROS EN LA ESTRATEGIA SALUD DE LA FAMILIA}

RESUMEN: Estudio cualitativo cuyo objetivo fue discutir los límites y posibilidades de la prescripción de medicinas por enfermeros en la Estrategia Salud de la Familia. Fueron entrevistados 11 enfermeros y la interpretación de las informaciones por medio del Análisis Temático resultó en cinco categorías empíricas. Los enfermeros se sienten capaces de prescribir medicinas en la consulta de enfermería; para ellos, la prescripción trae autonomía y valoración profesional y necesita de cuidado cuando ejecutada, para no traer riesgos a la salud de los usuarios. Esa práctica ocurre en los programas de salud pública, pero hace falta apoyo legal de la gestión de salud sobre el tema. Es necesario un diálogo entre la gestión, los enfermeros y los órganos representativos de la categoría para que la prescripción de medicinas sea realizada con ética y responsabilidad para el cuidado colectivo de salud. DESCRIPTORES: Enfermería; Cuidados de enfermería; Prescripción de medicinas; Salud de la Familia; Ética en enfermería.

\footnotetext{
*Extraído da monografia intitulada A Prática da Prescrição de Medicamentos pelos Enfermeiros na Estratégia Saúde da Família apresentada ao Curso de Enfermagem da Universidade do Estado do Rio Grande do Norte - UERN em 2011.

'Enfermeira do Hospital Maternidade Raimundo Venâncio de Sousa. Especialista em Auditoria em Serviços de Saúde. Membro do Grupo de Pesquisa Conhecimento, Enfermagem e Saúde das Populações da UERN.

${ }^{2}$ Enfermeira. Mestre em Cuidados Clínicos em Saúde. Professora do Curso de Graduação em Enfermagem da UERN. Líder do Grupo de Pesquisa Conhecimento, Enfermagem e Saúde das Populações. Orientadora.
} 


\section{INTRODUÇÃO}

A prática da prescrição de medicamentos é uma ação importante na consulta de enfermagem e imprescindível para o andamento do cuidado na Estratégia Saúde da Família (ESF). O ato da prescrição de medicamentos é regulamentado pela Lei n. 7.498/1986, que regula o Exercício Profissional da Enfermagem no Brasil; o Decreto n. 94.406/1987; e a Resolução do COFEN n. 271/2002, revogada pela Resolução COFEN n. 317/2007. Tal fato não retira a possibilidade do ato de prescrever medicamentos na consulta de enfermagem nos programas de saúde pública, visto que, a revogação não remete a um retrocesso do ponto de vista do agir ético-profissional do enfermeiro. Entretanto, este conjunto de leis e resoluções não devem ser os únicos caminhos para orientar/regulamentar o ato prescricional ${ }^{(1)}$.

O enfermeiro deve ter clareza sobre a legislação que regulamenta seu exercício profissional para que possa desenvolver uma prática clínica com competência e qualidade, realizando ações seguras à pessoa humana. Entretanto, estudo aponta o surgimento de problemáticas que demonstra

a tensão entre ações prescritivas e a liberdade de ação nos programas de saúde; a relação saber/ fazer na prática profissional; e a falta de nitidez na Portaria da Secretaria de Saúde e Ação Social que permite a prescrição de medicamento pelo enfermeiro $^{(2: 139)}$.

A população exige o cumprimento do direito à saúde conforme promulgado na Constituição Federal de 1988, pois a partir de então, a todo e qualquer cidadão foi concedido o direito universal a uma assistência resolutiva e de qualidade. Uma saúde compreendida de modo ampliado, para além do aspecto biológico do adoecimento. Assim, o acesso aos serviços de saúde tem como foco as ações de saúde integrais no sentido de responder as reais necessidades e problemas de saúde apresentados pelo individuo e comunidade.

Diante disto, faz-se imprescindível a real capacidade teórica e prática do enfermeiro em trabalhar protocolos de cuidado clínicos, discutidos coletivamente, ou até mesmo, de se tornar um 'prescritor' independente, detentor de conhecimento, que exerça o cuidado de enfermagem com autonomia, de forma que a consulta realizada pelo enfermeiro viabilize $o$ ato de prescrever medicamentos, conforme a regulamentação de cada país, estado e/ou município ${ }^{(3)}$. O respaldo jurídico dado ao profissional permitirá que ele compreenda o ato de prescrever como atividade da consulta de enfermagem, e,não como um fragmento isolado da mesma ${ }^{(2)}$.

Neste contexto, esta pesquisa objetivou discutir os limites e possibilidades da prática da prescrição de medicamentos pelos enfermeiros na ESF em Pau dos Ferros - Rio Grande do Norte, e buscou-se compreender o trabalho desenvolvido por eles na consulta de enfermagem, no sentido de entender sua visão sobre a prescrição de medicamentos na ESF.

\section{MÉTODO}

Trata-se de um estudo de abordagem qualitativa de caráter descritivo e exploratório. Esta abordagem considera o estudo da história, relações, representações, percepções e opiniões, produtos das interpretações que os humanos fazem a respeito de como vivem, constrói seus artefatos e a si mesmos, sentem e pensam ${ }^{(4)}$. A pesquisa foi aprovada pelo Comitê de Ética e Pesquisa da UERN sob a CAAE n. 0980.0.000.428-10, Folha de Rosto n. 325493.

A pesquisa foi realizada em Pau dos Ferros - Rio Grande do Norte, que tem população estimada de 27.733 habitantes, município este localizado na mesorregião do Alto Oeste Potiguar, distante $400 \mathrm{~km}$ da capital do Estado $^{(5)}$. Com respeito ao setor da Atenção Primária à Saúde (APS) o município apresenta cobertura de $100 \%$ da população adscrita em relação às equipes Saúde da Família ${ }^{(6)}$.

O convite para participar do estudo ocorreu por telefone e a coleta de dados foi agendada de acordo com a disponibilidade dos enfermeiros e realizada em seu local de trabalho. Para coleta das informações foi utilizada a entrevista semiestruturada aplicada a 11 enfermeiros atuantes nas ESF.

A gravação das entrevistas ocorreu entre os dias 05 e 25 de outubro de 2010 após a assinatura do Termo de Consentimento Livre e Esclarecido. As perguntas foram direcionadas aos seguintes pontos: (a) como é realizada a consulta de enfermagem; (b) como se dá a prática da prescrição de medicamentos durante a consulta de enfermagem; (c) em que situações ocorre a prescrição de medicamentos e o entendimento do profissional sobre legislação que reza sobre o ato de prescrever medicamentos; (d) a capacidade teórica dos enfermeiros para prescrever medicamentos; e (e) a compreensão dos profissionais sobre a importância da prescrição de medicamentos para a prática profissional.

Após a transcrição das entrevistas, estas foram analisadas seguindo as fases: (1) Pré-análise (leitura

Cogitare Enferm. 2013 Out/Dez; 18(4):743-50 
flutuante das transcrições dos depoimentos); (2) Exploração do material (busca pelas semelhanças e contradições dos depoimentos); (3) Tratamento dos resultados (construção das categorias) e (4) Interpretação (reflexão crítica dos resultados) ${ }^{(4)}$. Dos depoimentos emergiram cinco categorias empíricas que compõe os resultados desta pesquisa, a seguir apresentadas.

\section{RESULTADOS}

Para melhor entendimento dos resultados, apresentamos o perfil dos entrevistados: 10 enfermeiros que participaram da pesquisa são do sexo feminino e um do sexo masculino; cinco são enfermeiros graduados até o ano de 1998 e seis enfermeiros graduados até o ano 2007; três trabalham na zona rural e oito na zona urbana do município.

No que se refere à titulação, 10 enfermeiros são especialistas; e o tempo de atuação na ESF era de, aproximadamente, 5 anos.

\section{Categoria 1 - A Consulta de Enfermagem segue as normatizações dos programas de saúde pública, com ênfase na lógica da queixa-conduta e nas orien- tações educativas}

Os enfermeiros realizam a consulta de enfermagem de acordo com a queixa clínica do cliente; promove ações terapêuticas não medicamentosas, prescreve medicamentos e solicita exames de acordo com os depoimentos:

Durante a consulta eu escuto a queixa do paciente. [...] dou as orientações em cima do que ele me diz e, se houver necessidade, eu encaminho para a especialidade. Eu dou medidas alternativas para alívio dos sintomas até chegar o resultado do exame. (ENFERMEIRO-A)

[...] a consulta de enfermagem a gente sabe que é algo privativo de enfermeiro, ela é realizada dentro da ESF eu procuro fazer dentro do programa. Eu faço o exame físico; anamnese oriento de acordo com cada caso, algumas vezes prescrevo, solicito exames, $e$ outras encaminho para o médico quando necessário. (ENFERMEIRO-E)

Na fala do ENFERMEIRO-B fica evidente que há atividades com baixa procura, pela consulta de enfermagem, por parte do usuário. Em especial, os programas de acompanhamento da Hipertensão Ar- terial (HA) e Diabetes Mellitus (DM).

Eu confesso que tem uns programas, que nós temos certa dificuldade de atrair a clientela ate aqui [...] $o$ acompanhamento do HIPERDIA [...] como a clientela tá acostumada a receber a prescrição de medicamentos, então eles vão muito mais a consulta médica porque lá eles já saem com a consulta e a receita médica. A consulta de enfermagem, como é mais ouvir e fazer orientações acerca de alguns cuidados, eles não se mostram interessados em vir até aqui. (ENFERMEIRO-B)

\section{Categoria 2 - A prescrição de medicamentos pelos enfermeiros ocorre 'estritamente' nos programas de saúde pública}

A prescrição de medicamentos se mostra direcionada para os Programas de Saúde Pública do Ministério da Saúde. Foi enfatizado pelos enfermeiros que a prescrição de medicamento é reduzida a 'transcrição de medicamentos:

Conversando certa vez com o profissional médico, ele disse que o enfermeiro não faz prescrição e sim transcrição porque eu não estabeleço um critério para a conduta a ser prescrita. Eu transcrevo algo que está padronizado pelo Ministério da Saúde, e eu fiquei pensando até que ponto ele tinha errado, ou não, $e$ até que ponto o médico também não está fazendo apenas a transcrição, porque as patologias quando ele estuda também vem dizendo como serão tratadas. (ENFERMEIRO-B)

O ENFERMEIRO-A aponta que se prescrever fosse exclusivamente escolher a conduta medicamentosa, nenhum profissional na realidade estaria realizando-o.

[...] no caso de um HIPERDIA que a gente não pode prescrever a gente pode transcrever, então eu vou dar continuidade ao tratamento desse paciente através da transcrição, que não deixa de ser uma prescrição. Você estar medicando aquele paciente, embora você não tenha decidido a medicação, mas é uma prescrição também. (ENFERMEIRO-A)

Eu faço transcrição dentro do programa como a questão do HIPERDIA, então eu transcrevo a prescrição do médico. [...] tem pela questão do programa da ESF, lá eles dizem alguns sim, mas a gente sabe que na realidade quando você vai perceber você não pode, 
porque você também tem que ter uma lei municipal que lhe de essa autonomia de prescrever medicamento. Me detenho ao mínimo possivel. (ENFERMEIRO-G)

O ENFERMEIRO-B discorre sobre um dos maiores impasses da prática da prescrição de medicamentos pela categoria na ESF, que é a disputa por área privativa entre os profissionais da saúde sobre o ato prescritivo.

Em alguns casos, medicamentos que são prescritos os que são padronizados pelo Ministério da Saúde, eu me atenho apenas à parte puericultura, pré-natal, e o acompanhamento do câncer de colo de útero e mama. Os medicamentos para os demais programas [tuberculose, hipertensão e diabetes] eu não faço a prescrição mesmo com o medicamento sendo padronizado ou que esteja contido aqui no manual. Eu prefiro me abster disso, mesmo porque nós já temos um impasse com relação ao ato médico que ora está na evidencia de ser aceita legalmente, ora não. (ENFERMEIRO-B)

Há por parte dos enfermeiros uma preocupação em não deixar que a consulta de enfermagem se restrinja apenas à prescrição de medicamentos, bem como, tendo o cuidado em não realizar ações que sejam interpretadas e julgadas ilegais pelo Código de Ética Profissional:

[...] eu me resguardo muito em termos de prescrições de medicamentos, eu prefiro dar orientações acerca de mudança de alimentação, essas coisas assim. Porque a gente sabe que o medicamento, por si só, ele não tem eficácia. A gente precisa de outras medidas, então eu busco mais essas outras medidas para vir para a prescrição. (ENFERMEIRO-A)

A gente sabe que o enfermeiro, ele tem os seus limites, porque a gente sabe que o enfermeiro não pode prescrever todo tipo de medicamentos. (ENFERMEIRO-J)

\section{Categoria 3 - Os enfermeiros sentem-se capacitados para prescrever medicamentos}

Apresenta-se a seguir recortes de depoimentos que exemplificam esta categoria:

Se eu não tiver segurança, eu não prescrevo, então o que eu faço, faço com segurança. (ENFERMEIRO-A)

A prescrição de medicamentos que está padronizada pelo Ministério da Saúde, e para esse tipo de clientela a qual me referi, eu me sinto capacitado para prescrever, identificando o problema, estando dentro dessa padronização sim. (ENFERMEIRO-B)

Algumas medicações, sim. Pela questão do conhecimento que a gente tem, mas outras não, a gente sabe que não temos essa capacidade. (ENFERMEIRO-G)

Os participantes mencionaram o conhecimento, treinamentos e capacitações como instrumentos que subsidiaram, articularam e que forneceram base para o conhecimento e segurança, para executarem a prescrição de medicamentos:

De algumas coisas sim, eu já tive vários treinamentos, eu já trabalhei em outros municípios, mas tem coisas que quando eu não tenho muita segurança, como criança, a gente encaminha para o especialista, ou para o médico da unidade. (ENFERMEIRO-H)

Com certeza mais conhecimento e você tendo a capacidade, não é só tá ali no papel e fazer. Não, acho que tem que ter treinamento e conhecimento real. (ENFERMEIRO-H)

Dentro dos programas do Ministério da Saúde, sim. Eu transcrevo, eu trato consciente, porque como eu já tenho 20 anos de profissão, já passei por treinamentos, eu me sinto segura. (ENFERMEIRO-J)

Existe também uma preocupação por parte desses enfermeiros em assumir uma atividade de outro profissional, como consequência da ausência e comprometimento do profissional médico no serviço da ESF:

Porque a paciente às vezes pega uma fila enorme com o médico só para receber a transcrição do medicamento que com o enfermeiro o acesso é mais rápido. (ENFERMEIRO-J)

O médico, às vezes, exige que só vai atender $20 \mathrm{fi}$ chas. O enfermeiro, se chegar 50 pessoas, ele atende. (ENFERMEIRO-K)

\section{Categoria 4 - Os enfermeiros conhecem a legislação que orienta $o$ ato de prescrever medicamentos pela categoria}

Os enfermeiros relataram ter conhecimento sobre a lei 7.498 de 1986, que dá o direito do enfermeiro de 
prescrever medicamentos estabelecidos em programas de saúde pública e em rotina aprovada pela instituição de saúde. No entanto, mencionou-se a importância da decisão do município junto às ações prescricionais:

A gente tem uma oportunidade de fazer a prescrição de medicamentos no dia a dia, mas é como eu disse a você, a gente tem que ter também o aparato legal da Secretaria de Saúde, eles não dão essa cobertura pra gente. (ENFERMEIRO-G)

Não é só o COREN, mas a gente precisa ter a cobertura da Secretaria de Saúde, da prefeitura, documentação ser passada pela câmara, muitas coisas, precisa ter esse embasamento, que a gente não tem. (ENFERMEIRO-H)

O ENFERMEIRO-B, refere não se sentir à vontade, para trabalhar com a prescrição de medicamentos como atividade complementar a sua consulta.

[...] li essa resolução há algum tempo atrás e lembrando eu acho até que a resolução está um pouco exagerada com relação à prescrição, e eu não me sinto apto na realidade, e eu cito a cidade onde eu vivo a fazer as prescrições, segundo, o que nos dá direito a nossa profissão. (ENFERMEIRO-B)

Temos um relato que discorre sobre a ausência de articulação entre os órgãos competente COFEN/ COREN e os enfermeiros do município quanto ao repasse das decisões e novas regulamentações que são introduzidas no exercício profissional, e no código de ética desta categoria:

Nós nunca tivemos um repasse dessa lei ou dessa resolução, apenas eu tive a curiosidade de saber aquilo que me é cabivel tá prescrevendo legalmente. Eu tento sempre prescrever, algumas vezes a gente acaba deslizando, querendo fazer mais do que estar enquadrado nesta resolução. (ENFERMEIRO-D)

Foi evidenciada a importância da formação profissional, que se mostra insuficiente para capacitar os enfermeiros, de modo que estes possam realizar a prescrição de medicamentos, de acordo com os seguintes recortes:

A gente termina a faculdade e você sabe como é. Eles não preparam a gente para fazer a prescrição de medicamentos, pelo menos a que eu fiz não.

\section{(ENFERMEIRO-G)}

A gente quando termina a faculdade não tem tudo, né? A gente precisa de mais treinamento, informações não só escritas, a gente precisa de mais informações. (ENFERMEIRO-H)

O enfermeiro lança mão dos cursos de pós-graduação, pois considerar a graduação como insuficiente diante a realidade de sua prática, como pode ser comprovado pela fala a seguir:

[...] para Saúde da familia, a gente tinha que ter também uma especialização em PSF, porque quando você faz uma especialização em PSF, você está mais preparado para prescrever medicamentos. (ENFERMEIRO-G)

Categoria 5 - O ato de prescrever medicamentos pelos enfermeiros possibilita o reconhecimento e autonomia do profissional

Os enfermeiros relataram que a prática prescricional, no cotidiano da consulta de enfermagem, traz autonomia e valorização profissional, uma vez que a clientela por eles assistida, procura os serviços públicos de saúde na busca pela resolução dos seus problemas de saúde, como depoimentos:

A gente, enfermeiro, que tá dentro da ESF, nós somos aqueles que estamos mais presentes, isso já ajuda muito a resolver, muitas vezes, as necessidades dos pacientes e clientes já que nem em todos os momentos o médico está. (ENFERMEIRO-E)

Certeza, a gente fica até mais valorizado quando a gente passa. Para a gente já foi um ganho muito bom, os pacientes dão mais valor a nossa profissão. (ENFERMEIRO-K)

A falta e omissão da assistência médica foi uma das maiores razões citadas pelos enfermeiros como causadoras da expansão e rompimento dos limites da atuação do enfermeiro:

O problema é o acesso à consulta médica dentro da estrutura da ESF. O número de atendimento de consultas médicas é muito limitado nas UBS, então o enfermeiro passa a ser aquela segunda pessoa da referência para prescrever medicamentos e solicitar exames. (ENFERMEIRO-B) 
A autonomia do enfermeiro pra prescrever evita que a fila do SUS seja maior, evita que o paciente venha várias vezes à USF em busca de resolver uma coisa que eu, enquanto enfermeira, posso resolver. Então, além de melhorar o atendimento facilita, e humaniza $o$ atendimento ao paciente, e ainda melhora a nossa qualidade como enfermeira. (ENFERMEIRO-F)

\section{DISCUSSÃO}

A inserção dos enfermeiros no ato da prescrição de medicamentos nos programas de saúde pública se configura ainda como uma 'nova realidade' para a categoria. Pois, tal ação, para se tornar algo permanente no cotidiano do trabalho junto à ESF, necessita ser refletida e praticada com responsabilidade e competência teórica, ética e, principalmente, com conhecimento legal sobre os tramites que normatizam as atribuições do enfermeiro para realizarem a consulta de enfermagem $^{(7)}$. Os enfermeiros demonstraram satisfação em desenvolver o ato de prescrever medicamentos junto aos programas de saúde pública existentes no âmbito da ESF. Em algumas falas, percebeu-se certa ressalva aos limites legais de atuação, pois inexiste o apoio da secretaria de saúde do município juntos as ações prescricionais pelo enfermeiro.

$\mathrm{O}$ enfermeiro se vê entre o dilema de assistir a clientela e de não invadir o campo profissional de outra categoria, mesmo entendendo que o cliente necessita de um cuidado integral e multiprofissional,

a necessidade do compartilhamento do poder prescricional por outros profissionais, entre eles o enfermeiro, o que está em jogo é o aumento do acesso aos serviços de saúde e a resolutividade das ações ${ }^{(7: 14)}$.

Desse modo, a prática da prescrição de medicamentos é uma realidade/necessidade no trabalho do enfermeiro junto às atividades da ESF. Durante a realização das consultas de enfermagem, nos diversos programas de saúde pública existentes é, perceptível pontos nodais que se mostram como demandas a serem discutidas para viabilizar o cuidado integral e de qualidade para a população.

Em estudos anteriores ${ }^{(2,7)}$ observou-se que os enfermeiros da ESF, mostram-se insatisfeitos ao realizar a prescrição de medicamentos devido à falta de clareza quanto ao ato pela Gestão de Saúde Municipal. Igualmente, esta atividade já se constitui realidade em muitos países, como o Reino Unido, Espanha Canadá, Suécia e Austrália. A execução do ato prescricional pelos enfermeiros nestes países conseguiu trazer melhorias significativas para a população, tendo em vista que a incorporação desta ação pelos enfermeiros melhorou a comunicação e o acesso da população à assistência resolutiva e de qualidade, pois foi referida a ausência dos médicos nos serviços de saúde como uma das razões para justificar a atuação dos enfermeiros na prescrição de medicamentos ${ }^{(3)}$.

Os resultados do estudo fizeram emergir pontos a serem debatidos e revistos pelos atores envolvidos no processo do cuidado de saúde integral junto à comunidade (gestores, enfermeiros, equipe saúde da família), são eles: a) $O$ medo da consulta de enfermagem se transformar em mais um instrumento de medicalização; b) O receio dos enfermeiros em executar as ações prescricionais e invadir outra área profissional, nesse caso, o ato médico; c) A segurança desses profissionais em prescrever somente diante dos protocolos formalizados pelo Ministério da Saúde; d) A inexistência de protocolos terapêuticos discutidos coletivamente em nível local; e) A ausência de aparato legal no município para o desenvolvimento do exercício legal da prescrição de medicamentos pela enfermagem; f) As lacunas deixadas pelo processo de formação em nível de graduação e nos processos de educação permanente frente à realidade da prática do enfermeiro para realizar a consulta de enfermagem e prescrever medicamentos; e g) A efetiva participação dos órgãos fiscalizadores da categoria, nesse caso, os conselhos de enfermagem.

Para o enfermeiro que atua na ESF, a prescrição de medicamentos é uma ação integrante da consulta de enfermagem e esta, quando exercida com competência e responsabilidade, tem contribuído para a valorização e autonomia desses profissionais. Além de que, tem contribuído para a saúde da população, tendo em vista que sendo capacitados para prescrever medicamentos, os enfermeiros atuarão de forma resolutiva frente à assistência à clientela. Isso leva a comunidade a acreditar no trabalho e na capacidade clínica do enfermeiro, que ganha confiança, autonomia e credibilidade junto à sociedade ${ }^{(8)}$.

Garantir ao enfermeiro condições de atuar autonomamente, como reza a lei do exercício profissional, não significa dizer que ele terá que assumir a atividade de prescrever medicamentos quando não se sentir seguro e confiante. Pelo contrário, o direito de decidir em assumir tal atividade no cotidiano dos serviços de saúde deve ser acompanhado pela gestão local de saúde, que tem por dever proporcionar capacitação para 
seus recursos humanos.

As lacunas presumidamente deixadas pelos processos de formação universitária, decorrentes da carência de abordagem dos temas consulta de enfermagem e prescrição de medicamentos, no processo de ensino aprendizagem nos currículos sugerem avaliação dos currículos de enfermagem brasileiros. Para atuar frente às novas demandas de saúde, se fez necessária a participação desses profissionais em cursos, treinamentos e pós-graduações para que assim, apreendessem o conhecimento necessário para realizar as ações prescricionais a contento ${ }^{(9)}$.

Outro ponto de discussão que surge com a pesquisa são as dúvidas que os enfermeiros demonstraram em atuar em situações que fogem da sua capacidade legal de atuação profissional. Isso é um grande equívoco, pois os ditames legais asseguram ao enfermeiro, durante a consulta de enfermagem, realizar a solicitação de exames de rotina e a prescrição de medicamentos, quando necessário.

\section{CONCLUSÕES}

A prescrição de medicamentos pelo enfermeiro, no âmbito da ESF no município do estudo, deve ser debatida pela categoria e a gestão local de saúde, pois a prática profissional anseia por respostas e esclarecimentos para uma atuação autônoma. Para que tal ação se torne uma atividade plena e desempenhada pelos enfermeiros, é necessário a construção de protocolos terapêuticos discutidos pela gestão municipal e equipes de saúde, que ampare a categoria na realização das ações prescricionais no cotidiano dos serviços de atenção primária. Para tanto, é necessário o cuidado em não permitir que esses protocolos engessem a prática de cuidado da categoria.

Tal fato implica no livre direito desta categoria assumir essas atividades como complementares a sua assistência. O que se vê no cenário dos serviços de saúde brasileiros são disputas por áreas privativas de cada profissão, e assim, entendemos que, diante das novas necessidades sociais e profissionais que surgem, tendo em vista o novo cenário social que nos é apresentado, as categorias profissionais cada vez mais aproximam seu campo de atuação. Os muros que cercam as profissões vão se fragilizando e permitindo que as disputas se aproximem cada vez mais, isso vem acontecendo com a prática da prescrição de medicamentos. Cabe destacar que especificidade de conhecimentos, atividades, intervenções e responsabilidades na assistência ainda permanecerão segundo cada profissão. Do contrário, as profissões deixariam de existir.

Em contrapartida, as corporações profissionais se fecham nas suas práticas, não aceitando, de forma alguma que outras categorias profissionais venham a compartilhar suas práticas. Isso nos leva a refletir sobre a finalidade do cuidado a saúde. Será que a finalidade do cuidado está nas corporações profissionais ou na resolução das necessidades de saúde dos usuários?

No Brasil, o ato de prescrever medicamentos, além do universo dos programas de saúde pública, é um desafio. Entretanto, tal ação já se mostra como uma realidade de muitos países europeus e norte-americanos. Tal fato demonstra a total capacidade de enfermeiros se tornarem no futuro 'prescritores independentes' como já fazem os enfermeiros ingleses, espanhóis e canadenses.

Sobre a atuação do enfermeiro brasileiro, temos como experiências bem sucedidas a prática da prescrição de medicamentos realizada no estado do Ceará e, mais recentemente na cidade do Natal, Rio Grande do Norte, onde a Secretaria Municipal de Saúde, através de portaria, autorizou a prescrição de medicamentos, além da solicitação de exames de rotina e complementares, por enfermeiros da ESF, previamente estabelecidos em Programas de Saúde Pública, e em rotina aprovada pelas instâncias competentes do SUS, as quais normatizam os protocolos terapêuticos a serem trabalhados no município.

Cabe, portanto, aos profissionais da área da saúde compreender que os serviços de saúde, em especial, as ações da ESF, não se constituem num espaço de hegemonia de certas profissões sobre as outras. Pelo contrário, a ESF é lugar de atuação multiprofissional, no qual, os profissionais trabalham em equipe, atuando como um trabalhador coletivo de saúde, sendo respeitados os limites de conhecimento específicos de cada categoria profissional, e compartilhando determinados conhecimentos de maneira a não trazer riscos para a saúde das populações brasileiras. A escassez de discussão e trabalhos desenvolvidos sobre a temática em pauta se constitui numa realidade, isto porque a prescrição de medicamentos se conforma numa prática avançada da enfermagem, e surgiu decorrente das novas demandas sociais e de saúde da população. O debate sobre prescrição de medicamentos por enfermeiros na ESF deve ser cada vez mais incentivado a fim de trazer esclarecimentos para a categoria quanto o agir ético e os benefícios que tal ação traz para os usuários dos serviços de saúde brasileiros.

\section{REFERÊNCIAS}

1. Oguisso T, Freitas GF de. Enfermeiros prescrevendo 
medicamentos: possibilidadeseperspectivas. Rev. brasenferm. [Internet] 2007;60(2) [acesso em 12 jul 2011]. Disponível: http://dx.doi.org/10.1590/S0034-71672007000200003

2. Ximenes Neto FRG, Costa FAM, Chagas MIO, Cunha ICKO. Olhares dos enfermeiros acerca de seu processo de trabalho na prescrição medicamentosa na estratégia saúde da família. Rev. bras enferm. [Internet] 2007;60(2) [acesso em 12 jul 2011]. Disponível: http:// dx.doi.org/10.1590/S0034-71672007000200002

3. Courtenay M, Carey N, Burke J. Independent extended and supplementary nurse prescribing practice in the UK: a national questionnaire survey. Int J Nurs Stud. [Internet] 2006;44 [acesso em 10 out 2012]. Disponível: http://scele.org/web_scele/archivos/Prescricpion\%20 enfermera_2007.pdf

4. Minayo MCS, Sanches O. O desafio do conhecimento: pesquisa qualitativa em saúde. $11^{\mathrm{a}}$ ed. Rio de Janeiro: Hucitec; 2008.

5. Instituto Brasileiro de Geografia e Estatística (IBGE). Mapeamento Geográfico [Internet] 2009 [acesso em 10 set 2012]. Disponível: http://www.ibge.gov.br/home/ geociencias/default_prod.shtm\#MAPAS

6. Araújo JL de, Paz EPA, Moreira TMM. Hermenêutica e o cuidado de saúde na hipertensão arterial realizado por enfermeiros na estratégia saúde da família. Esc. Anna Nery. [Internet] 2010;14(3) [acesso em 05 nov 2011]. Disponível: http://dx.doi.org/10.1590/S141481452010000300018

7. Fagundes NC. Autonomia e uso de protocolos assistenciais: prescrição, transcrição de medicamentos, ações de apoio diagnóstico em enfermagem. Jornal da Associação Brasileira de Enfermagem - ABEn. [Internet] 2007;3(4) [acesso em 05 nov 2011]. Disponível: http://www.abennacional.org.br/download/a49n03-04. pdf

8. Ramos RFS, Borges LM, Brehmer LC de F, Ramos SL. Ethical education of nurses: indicators of change on the perception of professors. Acta Paul. Enferm. [Internet] 2011;24(4) [acesso em 10 mar 2012]. Disponível: http:// dx.doi.org/10.1590/S0103-21002011000400007

9. Araujo JL, Jorge MSB, Freitas CHA, Moreira TMM. O ensino da ética e da bioética no processo de formação do enfermeiro frente às Diretrizes Curriculares Nacionais. Cogitare enferm. [Internet] 2009;14(3) [acesso em 05 fev 2012]. Disponível: http://ojs.c3sl.ufpr.br/ojs2/index. php/cogitare/article/view/16190/10708 